\title{
Living Longer within Ageing Societies
}

\section{Sarah Harper ${ }^{1}$}

Published online: 4 September 2019

(C) Springer Nature B.V. 2019

The Journal of Population Ageing is now in its second decade. We are growing in size, will shortly be announcing our new editorial board, and are maintaining our reputation as a multi-disciplinary journal addressing issues around population ageing. We thought it would be timely to explore the continual rationale for the focus of JPA.

To grow old in a society where most people are old is fundamentally different from doing so in a society where most people are young. JPA thus consistently argues that the gerontological debate needs to be shifted away from a focus on older people per se, towards recognition that the age-structural changes which are occurring not only in all high income countries, but increasingly in middle income as well, have implications for all generations, and in particular for those in later life. The Journal thus considers the demographic dynamics, the impact of increasing longevity on issues such as pension provision and health-care, and of age-structural age or population ageing on wider societal aspects of housing, family and employment. We believe that it is important that policies are developed which support a multi-faceted approach to the ageing population, sound policy which will acknowledge the variation in population characteristics in different regions and localities - urban and rural, central and peripheral.

During the twentieth Century life expectancy in most high income countries gradually increased and the population slowly aged. Increases in life expectancy are driven by changing mortality rates and in particular the current decline in death rates amongst those over 65 is leading to an increase in the number and proportion of adults at very old ages. Population ageing, or age structural change, is driven primarily by low rates of child-bearing, so that the average age of the population increases as fewer young people enter the population.

As results not only are individuals living longer, they are doing so within populations which are in themselves growing older. In demographically young populations, there are high proportions of economically active individuals who may produce the wealth needed to support dependents, old and young. However, these societies may not place much emphasis on the wellbeing of older people as they comprise a small minority of the overall population. Conversely, demographically old populations have

Sarah Harper

sarah.harper@ageing.ox.ac.uk

1 University of Oxford, Oxford Institute of Population Ageing, Oxford, UK 
a lower proportion of economically active individuals and thus the responsibility of providing for old age dependency may be increasingly fall to the older person themselves.

The societal risks for ageing societies are well known. This shift from predominantly young to predominantly older populations raises concerns over the ability of nations to finance the social security and long term health and social care which are required to support a growing number and percentage of older dependents, at a time when the number and percentage of those who are economically active is declining. A second concern is about the ability to reconfigure health and long term care provision. A third challenge is around the reconfiguration of social institutions to address issues of intergenerational and intergenerational fairness, that is fairness and equity within and between different generations as population age and the support of individual wellbeing across the life course. Indeed, inequalities in access to resources, health, economic and social, are likely to remain a pressing concern over the coming decades.

Much of the concern around the economic challenge arises from the presumption that future older labour forces will be less productive and less innovative, and that an older population will consume less both with negative consequences for economies. However, in advanced economies at least, new cohorts of highly educated, skilled and increasingly healthy populations are approaching traditional retirement ages, and are increasingly remaining in economic activity - producing, consuming, and paying taxes.

The challenge is to make these societies more resilient to these demographic changes. Key questions are how to maintain wellbeing across the life course of these longer-lived individuals, and also how to redistribute resources within this new demographic. While currently everyone experiences a decline in mental and physical capacity as they age, this can however be mediated by life style/environment and increasingly in the future by bio-medical intervention, which may delay, though probably not prevent, the onset of this decline. This decline leads to an increased individual need for health and social care, and for a source of late life income, usually in the form of a pension. The ability of an individual to maintain wellbeing is compromised firstly by actual increases in dependency as their mental and physical abilities decline, and secondly by society constructing dependency, through such policies as requiring early withdrawal - retirement -from economic activity on grounds of age while the individual is actually still healthy and productive.

In addition, these demographic changes are occurring alongside the emergence of new social risks, arising from large-scale changes in the labour market and in household and family structures. In particular, it is likely that the twenty-first century will continue to see the current trend of the individual shouldering more risk and responsibility for more areas of life.

There are thus two separate, though linked, key dimensions to this demographic future which need to be considered.

Firstly is the impact of age structural change - the shift in population ages from predominantly young to predominantly older populations. Such a shift in the age structure of population has clear implications for the distribution and allocation of societal resources between age-groups and generations.

Secondly, increases in life expectancy and the growth in the number and proportion of oldest old will increase demands for the societal resources to support a potential lengthening of dependency and frailty at the end of our lives. This has implications for 
financial, health and social care support. It is linked to the general age structural change of the population as this longevity is occurring alongside below replacement child bearing, which is reducing the potential numbers of workers to provide this financial and practical support to the increasing number and percentage of older dependents.

While it is not argued that longevity increase and age-structural change have independent influences, it is recognised that longevity has a greater impact on the increased need for financial and care support for longer lives at a time when there may be fewer workers in the population. Age structural change will have a greater impact on the structure within which our lives are lived such as work, education, housing and families.

This demography, however, is not occurring in isolation. It is set in the context of the twenty-first Century, which is also seeing the emergence of new social risks - the result of large-scale change in the conditions of central features of social life: changes in the labour market and changes in household or family structures. The effects on richcountry labour markets of globalization and fast-moving technological innovation have been significant. There has been a rapid and steep decline in the relative importance of manufacturing in older industrialised economies and this has been matched by an equally rapid growth in the service sector and more precarious forms of employment. The rapid pace of technological innovation has opened up a range of knowledgeintensive economies that put a premium not only on the level of education in the work force, but also on its flexibility and adaptability. At the same time there have very large increases in female participation in the workforce and most women now enter the labour market with similar aspirations for lifetime employment and career development as men. Young people entering the labour market find themselves in a very different world from that which prevailed when the 'baby-boom' generations entered the workforce.

Families and households are changing as well, and for some demographers these changes are of sufficient significance to be considered as a second demographic transition. As well as a marked decline in fertility to sub-replacement levels, there have been importance shifts in the permanence and homogeneity of long-term relationships between couples. Co-habitation and childbearing outside marriage are becoming more much common, and unions of both types - whether marriage or cohabitation - are less stable. There has been an observable shift from ordered life course transitions, marriage and nuclear families to flexible life course organization and multiple lifestyles.

Furthermore, twenty-first Century Population ageing is taking place within existing institutional structures, mainly inherited from the twentieth Century. The appropriateness of financial and health institutions and programmes, designed for the population of the twentieth century, for the individual life courses, familial and societal structures of the twenty-first century may be questioned (Harper, 2012). In particular, there are questions to be addressed around the capacity of individuals and households to make the relevant adjustments to savings behaviour, labour productivity, family intergenerational transfers, and investment in their own human capital, and also around the capacity of institutions to make the relevant adjustments to enable arrangements for savings, labour supply, public intergenerational transfers, and investment in human capital. Two particular challenges will be how to manage the expectations of relatively affluent upcoming cohorts of older adults who wish to maintain quality of life and 
health in later life, while also tackling the likely increasing inequalities between different income/asset groups in later life.

The key challenge for governments is thus to maintain wellbeing across the life course and within and between generations as the age structure shifts towards older ages and with implications for resource redistribution. A goal of most policies in this context is to ensure that citizens regardless of generation, gender, socio-economic background or ethnicity should have access to health care, education, and supportive social and physical environments, enabling the achievement and maintenance of wellbeing across the life course.

Over the coming decade the Journal of Population Ageing will continue to publish high quality papers, which reflect the complex issues which are emerging in all nations and regions as the world shifts to a predominantly older population.

Pulisher's Note Springer Nature remains neutral with regard to jurisdictional claims in published maps and institutional affiliations 